\title{
Pipe Internal Grooving Using Closed Magnetic Field System: A Novel Method
}

\author{
Mohd Ridha bin Muhamad a,b, Mehedy Hasan Rony a, Mohd Nashrul Mohd Zubir \\ a,b, Farah Arina Ibrahim ${ }^{\mathrm{a}}$, Mohamed Moustafa Abdelhalim Ahmed Eid ${ }^{\mathrm{a}}$ \\ ${ }^{a}$ Department of Mechanical Engineering, Faculty of Engineering, University of Malaya, \\ 50603 Kuala Lumpur, Malaysia \\ ${ }^{\mathrm{b}}$ Centre of Advanced Manufacturing and Material Processing (AMMP Centre), University of \\ Malaya, 50603 Kuala Lumpur, Malaysia \\ *Corresponding author: E-mail: ridha@um.edu.my; Tel.: +603-7967 6806; Fax: +603-7967 \\ 5330
}

\begin{abstract}
The present work proposes an innovative method to form microgrooves on a tube internal surface through a new machining mechanism based on the principle of magnetic force for a greater flexibility and lower mechanical constraint. A newly designed machine equipped with a Magnetic Grooving Tool (MGT) was designed and fabricated for this purpose. The tool that consists of a pair of magnets is positioned in the pipe to be pulled by another pairing magnets set at the pipe external side. These four magnets are arranged in sequence of N-S$\mathrm{N}-\mathrm{S}$ direction so that it creates a closed magnetic field circuit which has a greater pulling force. By controlling the magnet pair at the pipe's external side in the linear and rotational direction, the MGT is moved in both directions and simultaneously pulled towards the pipe surface to form the microgrooves. Experiment has been carried out by adjusting the internal and external magnets size combination and its distance to vary the magnetic strengths. The effect of magnetic pull force on the grooving dimension was examined by using an optical microscope and further analyzed using a 3D optical surface profile analyzer. The method was proven to capable of producing microgrooves on the internal surface of the copper pipe. The maximum groove depth of $75.55 \mu \mathrm{m}$ was recorded by using the magnet size 10x10x40 $\mathrm{mm}$ and distance between magnet and workpiece of $2.5 \mathrm{~mm}$.
\end{abstract}

Keywords: Closed magnetic circuit, Pipe manufacturing, Internal groove, heat exchanger, magnetic tool, linear motion.

\section{Introduction}

Research on improving heat transfer efficiency in heat exchanger has been at the forefront subject of interest by thermo fluids researchers (1). Within the current technological perspective, one of the prospective approaches is to gain control over the boundary layer domain where heat and mass transfer dominates. Retrospectively, researchers have adopted both passive and active techniques in order to modulate the boundary layer (2). Active heat transfer augmentation technique deals with direct control over the fluid interaction within the vicinity of the solid-liquid interface via external excitation method (3-6). This method can be classified into two categories: active methods where the channel walls are fixed and active methods where the walls are moved 
by external forces (7). In fixed channel method, the excitation acts to change the solid-liquid boundary with the heat transfer surface remain in stationary. The state of the art of this category includes electrohydrodynamic, impinging jets, and electromagnetic based fluid control mechanism. On the other hand, moving boundary method relies on physical excitation of solid motion in contact with the fluid media (3). The motion alters the fluid physical characteristics which either impact the heat transfer of the adjacent surface or directly perturb the boundary layer of the wall subjected to the motion. The dynamic oscillation of the heat transfer surface provides the required pumping effect which allows the heat exchanger to be independent of process parameters in governing the heat transfer, thus serving as multifunctional device. On the other hand, passive heat transfer augmentation technique involves physical modification of the surface in contact with the fluid via several approaches. This includes, surface profile alteration, insertion of flow swirling devices and modifying fluid properties (8). It is worth to highlight that significant increase in heat transfer coefficient has been recorded under passive and active heat transfer augmentation approach, underlining their prospect to solve the current limitation of heat management in wide spectrum of applications (9)

Focusing on surface profile alteration approach, the idea lies on increasing the total surface area, modifying the surface energy as well as generating artificial turbulence through flow obstruction and expansion. This would promote flow mixing and thinning at the viscous sublayer region, leading to heat transfer augmentation. Increasing the surface roughness via sandblasting technique produces uneven surface with scattered bumps to induce wake formation and thus enhancing the recirculation which acts as vehicle to transport the heat at the near wall region (10, 11). On the other hand micro-fabrication technique such as surface printing and embossing have been adopted to produce more structured surfaces aiming at increasing the heat transfer surface and generating secondary recirculation flow (12). The above concept has been widely adopted to produce wicked and herringbone tubes with varying cross sectional profiles to induce the turbulence (13).

A class of passive heat transfer enhancement techniques that involves surface modification to promote turbulent flow and increase the heat transfer surface area also known as the "rough surface technique" (14). Many modified tubes with grooved surfaces are made using this technique. It is well known that the critical aspect for gaining heat transfer involves modifying the boundary layer where most of the physical phenomena dominate (14). Internally grooved tubes facilitate swirling action of fluid to better mixing and reduce the boundary layer thickness in comparison to a smooth tube. Due to effective heat transfer augmentation, they are widely used instead of smooth tubes in heat exchangers. Thus, fabricated grooved tubes show better overall thermal performance and are widely used in modern heat exchangers as they are instrumental in heat transfer augmentation (15). Ebisu and Torikoshi et al. (12) stipulated that heat transfer enhancement inside inner grooved tubes is attributed to the formation of a uniform film layer at the sidewall of the tube which increases the wettability of the surface.

L. Leal et al. (6) briefly explained about passive techniques that has been widely used and resulted remarkable performance achieved in many application such as heat exchanges. Inner surface modification of close conduit has been a persisting challenge to researchers due to the tool size limitation and restriction of the inner surface profile. Extrusion process is the typical approach to achieve different cross-sectional profile of the conduit. Wicked tubes are fabricated using this technique (13). However, the profiles produce by extrusion only vary in cross sectional profile 
without any change in axial direction. While it is understood that the flow is directed axially along the tube, this configuration limits the optimum potential for the pipe to achieve high heat transfer enhancement. Another unconventional route to produce modified inner surface is through embossing technique by which herringbone tubes are typically made (11). In this method, a flat strip of metal is embossed or stamped using die with specific configuration, subsequently rolled into round tubes, and inductively welded. Researchers have directed their attention into this kind of pipes due to its favorable characteristic to induce wake and disruption of boundary layer via recirculation process. However, the welding required for connecting the two ends of the flat plate raises concern on the durability and efficiency of the product since it is well known that seamless pipes produced without any welding demonstrates higher strength in comparison to welded pipes. In addition, the increase in heat transfer comes with an adverse effect of significant pressure drop increase due to higher fin height that aggravate flow obstruction.

Ball spinning is a process to produce wall-thinned high-precision tubes with small diameters has been utilized in recent years to produce grooves inside grooved copper heat pipes, such as triangular, rectangular, trapezoidal, and inverse trapezoidal types, which results in different heat transfer capability. How to produce ideal inner micro grooves is the crucial problem to the copper heat pipes. Numerous researchers are attempting to create different types of equipment's to meet their necessities by utilizing ball spinning process, for example to produce conical wall tubes, and stepped wall tubes. Studies on this technique focused on the relationship among the ball size, the axial feed rate and the quantity of balls $(16,17)$. An oil-filled ball spinning process was adopted to machine an axially directed inner micro grooves by extruding the copper tube with fixed multitooth mandrel by LI Yong., et al. The effects of the mandrel geometry and spinning process parameters were studied to find out the optimum machining conditions (18). H T Lim., et al. (19) adopted this technique in his study and highlighted a significant challenge in producing a narrow groove about $100 \mu \mathrm{m}$ when it comes in the shape of a sharp corner angel.

A new technique of machining method to produce micro groove which is called Deformational Cutting (DC) was introduced by Bauman Moscow state university in 1998 (20). Utilizing DC-strategy it is feasible to make microgroove hairlike constructions on a metal tapes and sheets with a width of slender hole from units of microns or more with pitch from 50 microns with groove tallness up to 6-7 pitches for nonferrous metals. The tape (sheet) pulls on the drum, introduced on screw-cutting machine. The way toward scoring is equivalent to turning cut, yet without chip. The cutting apparatus is micro grain carbide embed, having different geometry. It can produce minimum groove width of 4 micrometers. It is also feasible to get the length of fin site up to 2 meters with drum diameter $640 \mathrm{~mm}$ (21). This technique finds significant potential in heat exchange intensification, by finning of pipes for heat exchanger, as well as surfaces for pool boiling and vapor evacuation diverts in circle heat pipes (7, 22-25).

A. E. Bergles., et. al. have adopted that by improving heat transfer efficiency in heat exchanger has been most important key subject of interest by thermo fluids researchers (26). Heat transfer enhancement increased up to $63 \%, 58 \%$ and $47 \%$ for circular, trapezoidal and rectangular grooves (27). R.Ponnappan et. al. (28) described that, the ratio, $\mathrm{r}_{\mathrm{c}} / \mathrm{r}_{\mathrm{h}}$ of this groove diverse from 1.24 to 2.12 (where $r_{c}=$ capillary radius and $r_{h}=$ hydraulic radius). A trapezoidal groove was made by the metal rolling method and rectangular groove done by the dicing saw cutting method. These fabrication methods have many limitations and disadvantages. Physically fabricated trapezoidal or rectangular grooves are still too enormous $(w \geq 0.2 \mathrm{~mm})$. The current groove forming method of 
the industry for example rolling, dicing saw cutting, electrical discharging machining, etc., are complicated and expensive, and it is hard to make deep grooves $(w / \delta>4)$ without the harming of the groove walls. Furthermore, circumferential fluid distribution (an essential part for evaporator priming) is not possible in the solid-walled grooves.

In recent years, various non-conventional approaches to perform inner-surface modification has been explored. The advanced finishing techniques with abrasive has been discovered to be used to achieve nanometer surface finish and dimensional tolerances (29). Kumar et al. (30) concluded magnetic abrasive finishing with permanent magnet and direct current are commonly used for surface internal and external modification and has given great results on surface roughness. Earlier in 1986 Shinmura et. al. introduced Magnetic Abrasive Finishing (MAF) by closed magnetic field (31). Magnetic Abrasive Finishing (MAF) is one of those non-conventional high precision finishing processes and is considered as one of the most advanced techniques among the manufacturing process in the domain of surface modification (30). Ridha et al. (32) have designed and developed an apparatus to realize the desired surface finishing of aluminum tubes with greater control on the surface profile and uniformity. They incorporated a set of permanent magnets on both the inner side and outer side of the tube. The outer magnet set which was mounted at the jig surface allowed to control the movement of the inner magnet via close magnetic circuit configuration. The demand for products with high-quality surface finishing has surged in the past decade. This high degree finished product demand made industries, which is working in surface finishing, to study and develop alternate machining techniques that could deliver desired target where conventional machining techniques such as lapping, grinding, honing, polishing, and brushing were not able to cope up with.

On this note, the present work has adopted magnetic abrasive finishing (MAF) technique coupled with the introduction of Magnetic Grooving Tool (MGT) to achieve internal grooving of the inner conduit. MAF is believed to be the appropriate technique to overcome the challenges due to the flexibility in tool design and miniaturization as well as possessing the ability to create different grooving patterns and profiles by varying the fabrication parameters. This would allow more control on the grooving parameter (i.e. depth, cutting profile, roughness). 


\section{Experimental procedures}

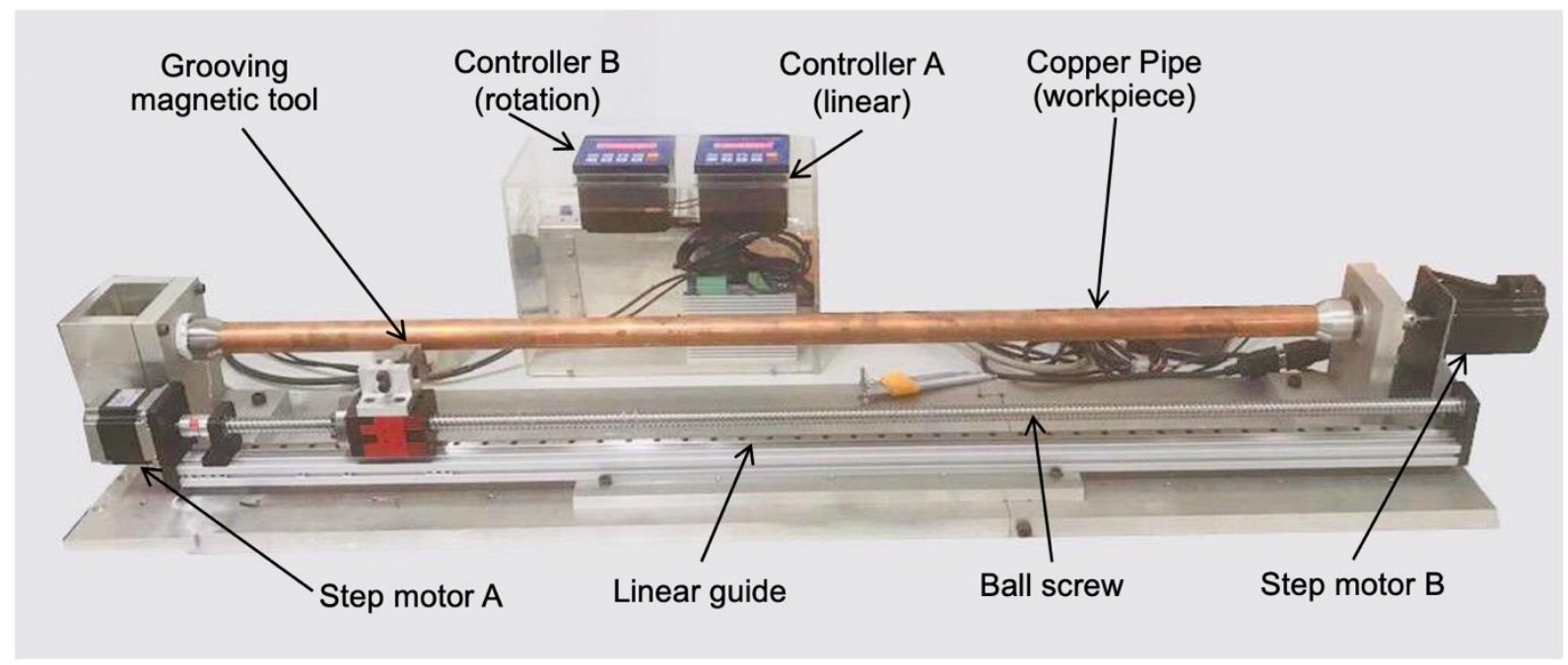

(Fig. 1 Photograph of the Magnetic Grooving Machine, MGM-1)

A new grooving machine tool introducing the closed magnetic circuit was designed and fabricated. This machine has three main constructions; the axes controller, the workpiece holder and external magnet unit attached on a ball screw system. Figure 1 shows the photograph of the setup for internal tube grooving. The workpiece is AS1571 grade for refrigeration having wall thickness $0.91 \mathrm{~mm}$ and $28.6 \mathrm{~mm}$ outer diameter, placed round jig as shown in Figure 1. Inside the pipe, a Magnetic Grooving Tool (MGT) is placed to perform the grooving. This tool consisted of a pair of $\mathrm{Nd}_{2} \mathrm{Fe}_{12} \mathrm{~B}$ neodymium (10x10x10 mm) magnet which is secured in placed by setting it in the epoxy. At the same position on the pipe external side, another pair of magnets are positioned connected to the linear axis system. These four magnets are positioned in N-S-N-S sequence so that it creates a closed-magnetic field circuit that are stronger in pulling force. Figure 2(a) shows the MGT and its position in the pipe, and the magnets sequence to create a closed-magnetic field circuit. This structure creates a magnetic pulling force to press the MGT towards the pipe internal surface. Figure 2(b) shows the details of tool tip shape. The tip is made of tungsten carbide, fixed on the center of MGT that contact on the pipe internal surface. This way, the tool is pulled towards the pipe surface by the magnetic force and the tool tip is pressed onto the surface. Next, the pipe is rotated and the MGT is moved in a linear direction. These two-axis movement creates a relative movement on the tool tip to create a spiral groove onto the pipe internal surface. Then, the groove on the workpiece was evaluated its shape and dimensions by grinding and polishing its section to view the groove at the edge and on the surface. The parameter details is shown in Table 1. The magnetic field strength was adjusted by varying the gap between external magnet and pipe external surface. Three magnet combinations for internal and external magnets were used in this study, combination 1, 2 and 3 to adjust the force strength as shown in Table 2. The depth of the groove was investigated by using a light optical microscope BX-61 (Olympus, Japan) and 3-dimensional optical surface texture analyzer Alicona Infinite Focus G5 (Bruker, Austria). 


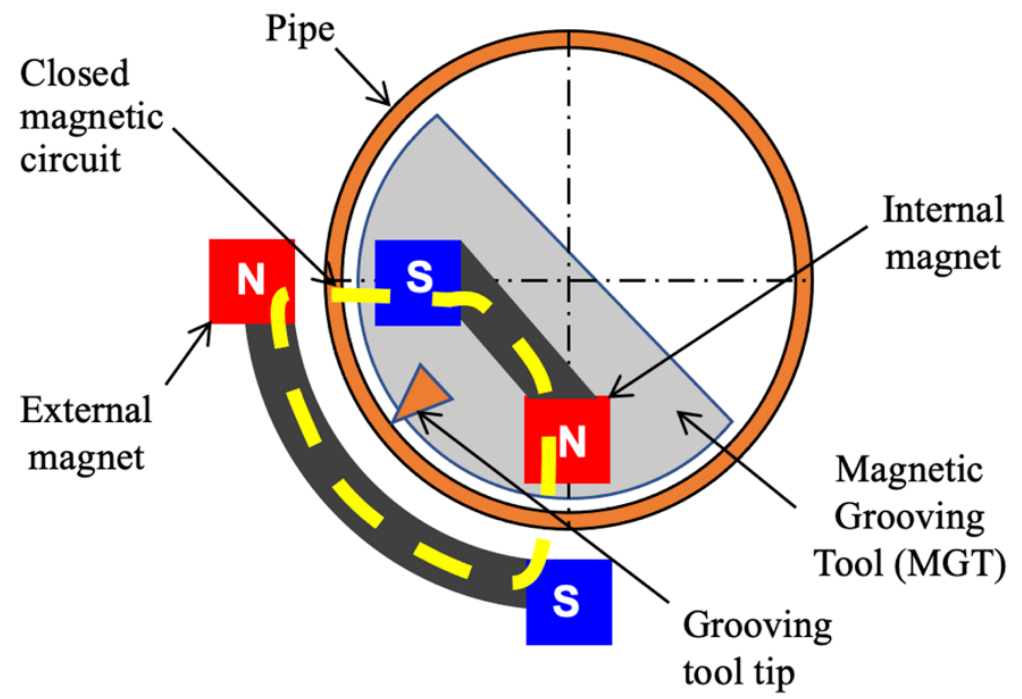

(a)

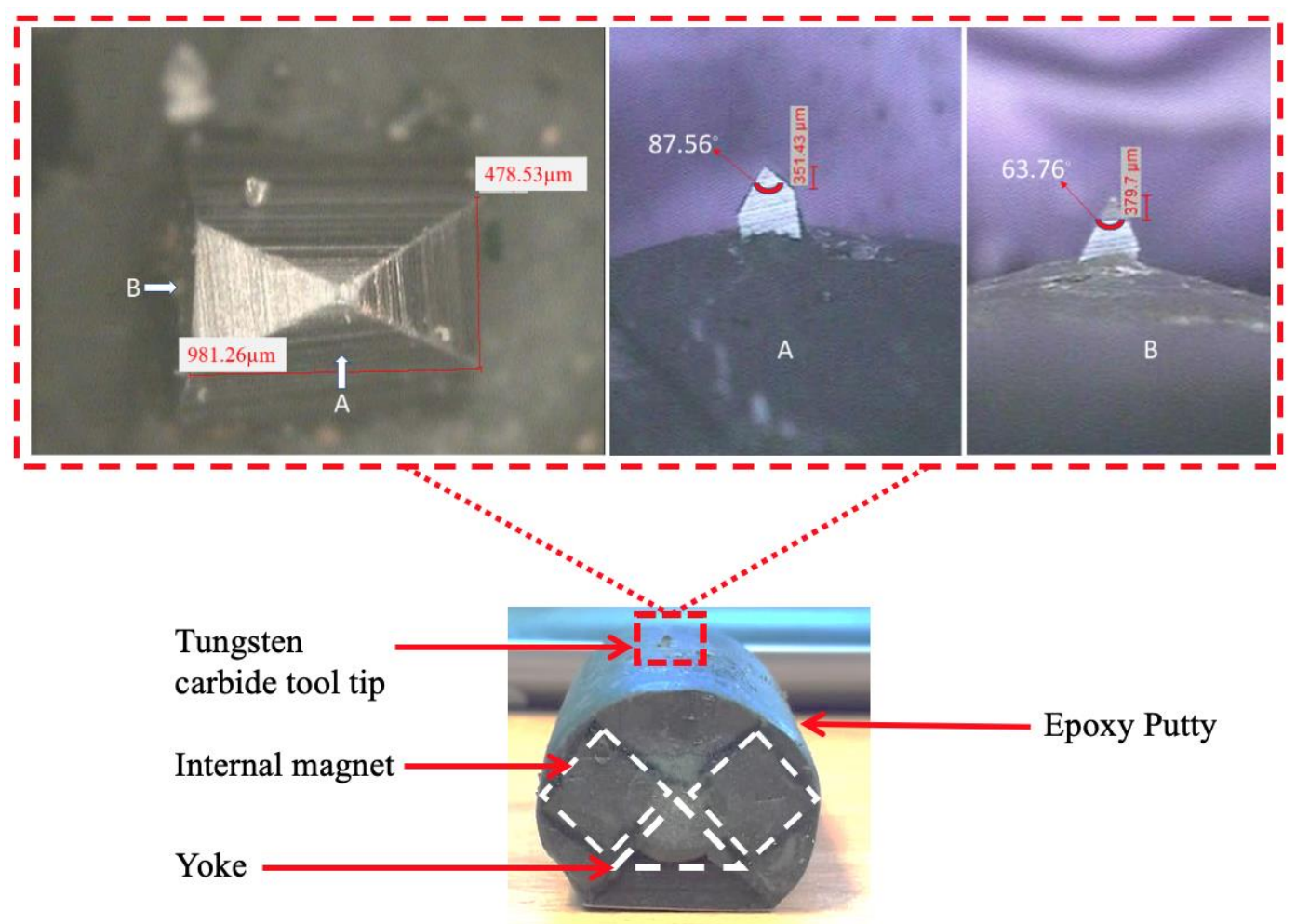

(b)

(Fig. 2 Magnetic Grooving Tool details. 2 (a) Schematic of pipe internal grooving by the principle of closed-magnetic circuit, 2(b) Construction of the tool and the tip shape. 
Table 1 Experimental conditions

\begin{tabular}{|c|c|}
\hline Workpiece $(\mathrm{mm})$ & $\begin{array}{l}\text { AS1571-1985, ASTM B280 Copper, } 0.91 \text { wall thickness } \\
\text { and } 28.6 \text { outer diameter }\end{array}$ \\
\hline Tool material & Tungsten carbide \\
\hline \multirow[t]{3}{*}{ Magnet (mm) } & $\mathrm{Nd}_{2} \mathrm{Fe}_{12} \mathrm{~B}$ neodymium permanent magnet \\
\hline & Dimension 10x10x10 and 40x10x10 \\
\hline & $\begin{array}{l}\text { Remanence (Br) is } 1.0-1.5 \mathrm{~T} \text { and coercivity (Hci) is } 0.875- \\
2.79 \mathrm{MA} / \mathrm{m}(30,31) \text { Type } \mathrm{N} 52\end{array}$ \\
\hline Linear motion speed $(\mathrm{mm} / \mathrm{s})$ & 0.3 \\
\hline Workpiece rotation speed (rpm) & 18 \\
\hline $\begin{array}{l}\text { Gap between magnet and } \\
\text { workpiece }(\mathrm{mm})\end{array}$ & $2.0,2.5,3.0,3.5,4.0,4.5$ and 5.0 \\
\hline
\end{tabular}

Table 2 Section layout of magnet combination for different magnet size in the pipe.

\begin{tabular}{|c|c|c|}
\hline $\begin{array}{l}\text { External magnet } \\
(10 \times 10 \times 10 \mathrm{~mm})\end{array}$ & $\begin{array}{l}\text { External magnet } \\
(40 \times 10 \times 10 \mathrm{~mm})\end{array}$ & $\begin{array}{l}\text { External magnet } \\
(40 \times 10 \times 10 \mathrm{~mm})\end{array}$ \\
\hline & & \\
\hline
\end{tabular}


Table 1 Magnet combination, gap and average surface roughness measurement

\begin{tabular}{|c|c|c|c|}
\hline No & Combination & Gap $(\mathrm{mm})$ & $\begin{array}{c}\text { Average roughness } \\
(\mu \mathrm{m})\end{array}$ \\
\hline 1 & 1 & 2.0 & 2.20 \\
\hline 2 & 1 & 2.5 & 2.33 \\
\hline 3 & 1 & 3.0 & 3.02 \\
\hline 4 & 1 & 3.5 & 2.92 \\
\hline 5 & 2 & 2.0 & 8.95 \\
\hline 6 & 2 & 2.5 & 6.98 \\
\hline 7 & 2 & 3.0 & 11.83 \\
\hline 8 & 2 & 3.5 & 10.21 \\
\hline 9 & 3 & 2.0 & 72.85 \\
\hline 10 & 3 & 2.5 & 75.51 \\
\hline 11 & 3 & 3.0 & 60.82 \\
\hline 12 & 3 & 3.5 & 58.93 \\
\hline 13 & 3 & 4.0 & 29.46 \\
\hline 14 & 3 & 4.5 & 25.60 \\
\hline 15 & 3 & 5.0 & 22.02 \\
\hline
\end{tabular}

\section{Results and discussion}

\subsection{Magnetic field analysis}

Two magnet combinations were analyzed in this experiment. The combination $1(10 \mathrm{~mm}$ magnet) and combination 3 (40 mm magnet) were simulated using finite element method magnetics (FEMM). Analysis of magnetic field energy and magnetic strength are shown in Figure 3(a) and 3(b). The magnetic strength density by creating closed-magnetic field by adding connecting yoke in between the four magnets as shown in Figure 3(a) and 3(b) density plot. The magnetic field energy is lowest in $10 \mathrm{~mm}$ magnet in Figure 3 (a). However, considering the size ratio, the $40 \mathrm{~mm}$ combination has the lowest value of 0.28354 Joules per $10 \mathrm{~mm}$ magnet size. The lowest magnetic field energy per area indicates the strongest pull force. 

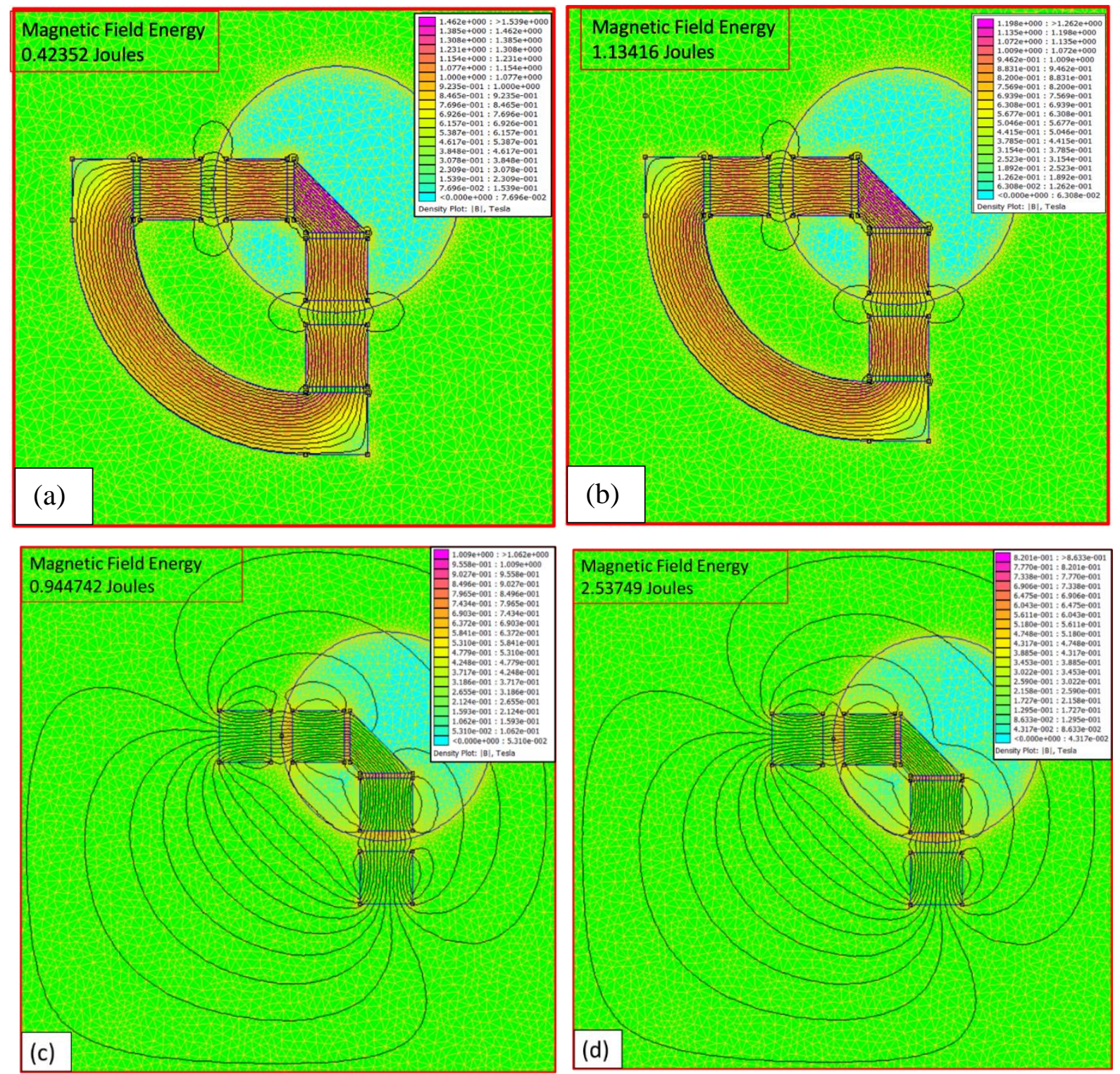

(Fig. 3 Finite element method magnetics (FEMM) analysis of magnetic field energy for closedmagnetic circuit for (a) combination 1 (10/10 mm magnet), (b) combination 3 (40/40 mm magnet) and open-magnetic circuit for (c) combination 1 (10/10 mm magnet), (d) combination 3 (40/40 mm magnet))

\subsection{Groove Profile}

The grooves section profiles were analyzed by means of an optical microscope (Olympus, BX61). Figure 4 shows the photographs of the workpiece copper pipe section after the grooving. Internal grooves lines were successfully formed as indicated by the red arrows. By adjusting the distance between external and internal magnets, groove depth on the pipe internal surface could 
be controlled. A significantly deeper grooves were formed using combination 3 magnets could be observed in Figures 4 (i) 4(1).

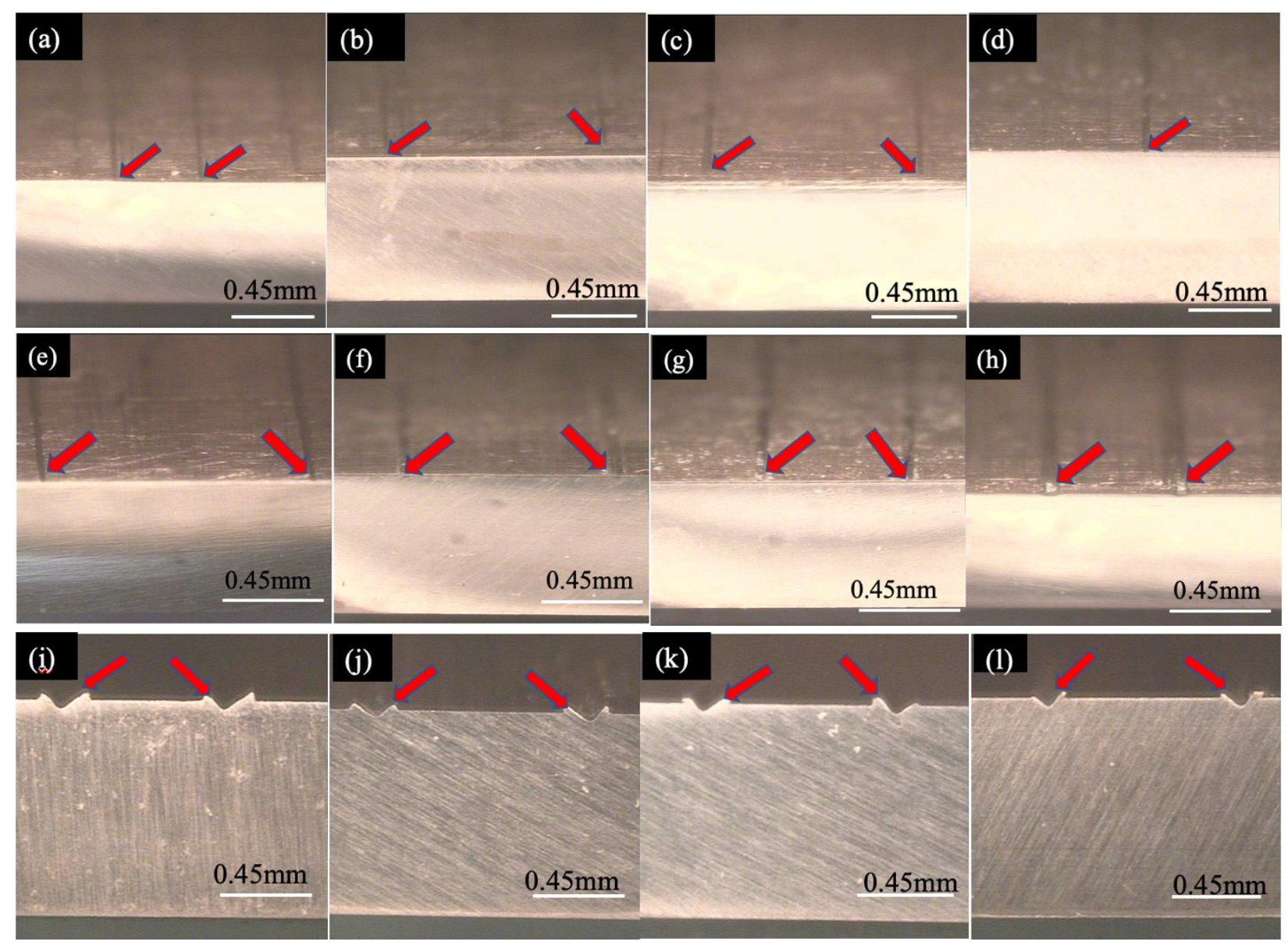

(Fig. 4 Photographs of grooves formed using Combination 1 (10/10 mm magnet) 4(a) $2 \mathrm{~mm}$ gap, 4(b) $2.5 \mathrm{~mm}$ gap, 4(c) $3 \mathrm{~mm}$ gap, 4(d) $3.5 \mathrm{~mm}$ gap; Combination 2 (40/10 mm magnet) 4(e) $2 \mathrm{~mm}$ gap, 4(f) $2.5 \mathrm{~mm}$ gap, 4(g) $3 \mathrm{~mm}$ gap, 4(h) $3.5 \mathrm{~mm}$ gap and Combination 3 (40/40 mm magnet) 4 (i) $2 \mathrm{~mm}$ gap, 4(j) $2.5 \mathrm{~mm}$ gap, 4(k) $3 \mathrm{~mm}$ gap, 4(I) $3.5 \mathrm{~mm}$ gap)

\subsection{Groove Profile optical surface texture analyzer}

A 3D optical surface texture analyzer Alicona Infinite Focus G5 (Bruker, Austria) was used to measure the surface roughness and profile of the groove. The $\mathrm{V}$-shape groove observed under the 3-dimensional laser profiler Alicona, 3D view of the grooved copper pipe surface is shown in figure 5 . 


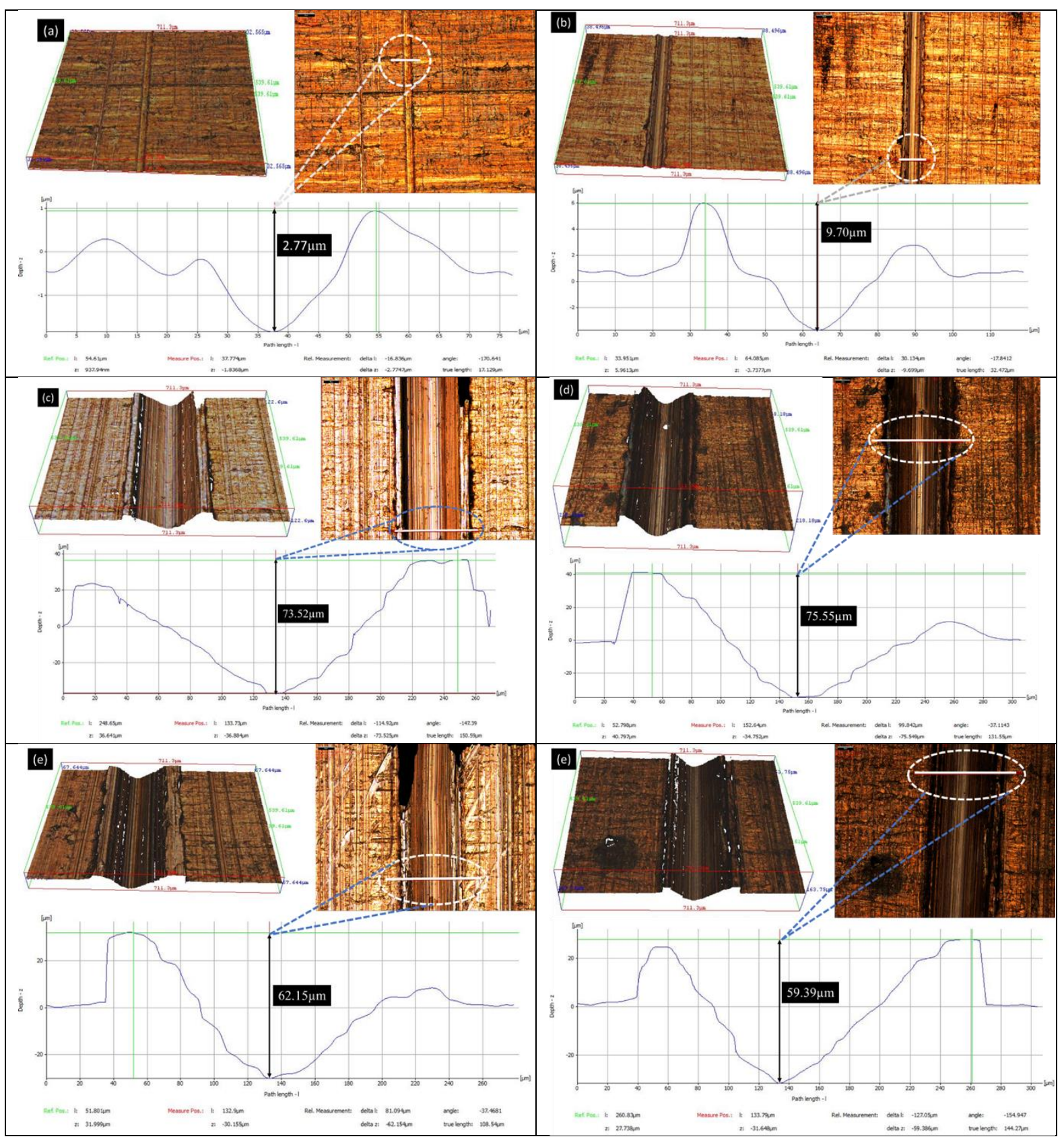

(Fig. 5 The 3D view and micrograph of the grooves profile formed using magnet Combination 1: 5(a) $2 \mathrm{~mm}$ gap, Combination 2: 5(b) $2 \mathrm{~mm}$ gap, and Combination 3: 5(c) $2 \mathrm{~mm}$ gap, 5(d) $2.5 \mathrm{~mm}$ gap, $\mathbf{5}$ (e) $3 \mathrm{~mm}$ gap, $\mathbf{5}$ (f) $3.5 \mathrm{~mm}$ gap). 


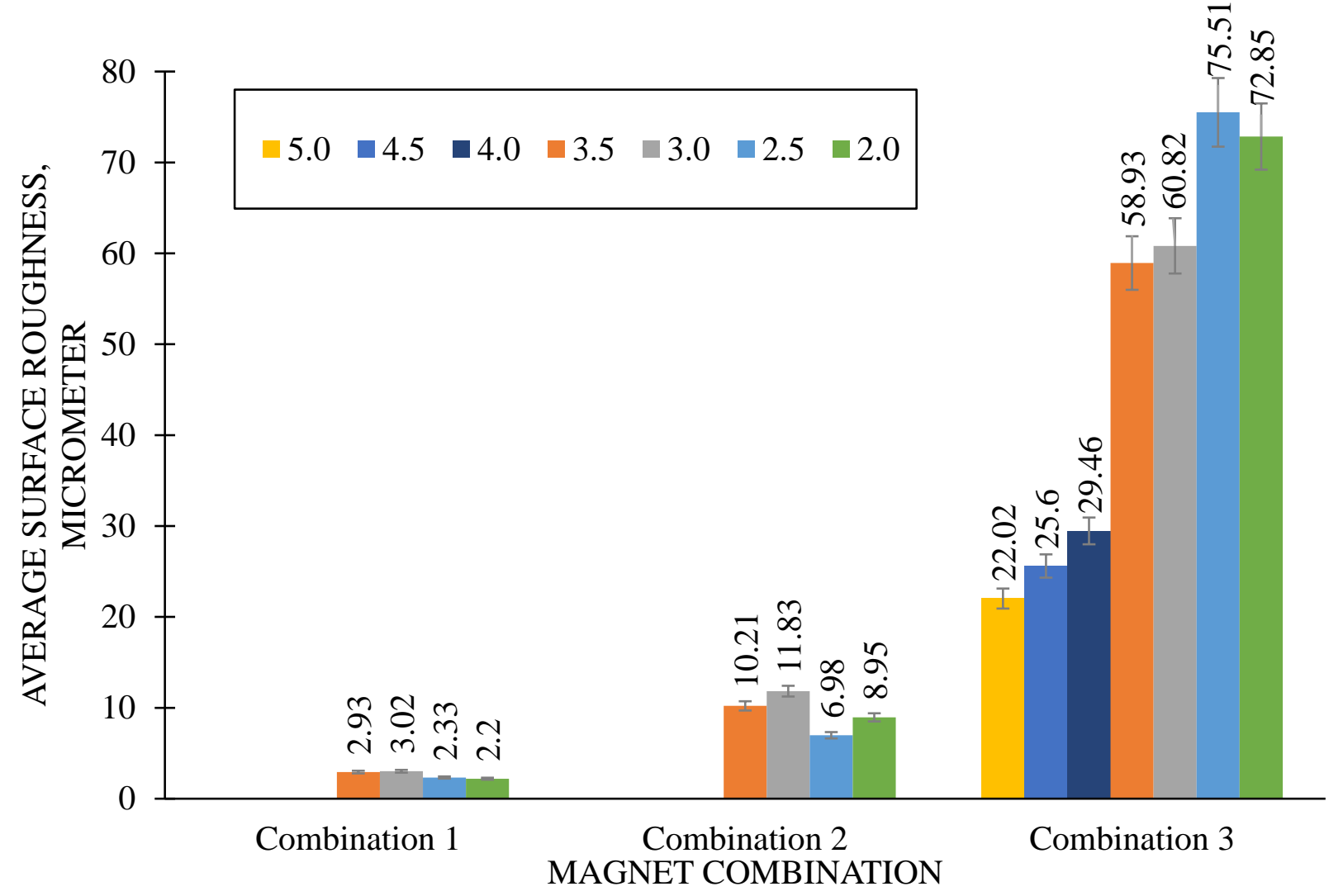

Figure 6. Groove depths for different magnet combinations and gaps (mm).

\section{Discussion}

The magnet combination 1 created grooves depth at 2.20, 2.30, 3.02 and $2.93 \mu \mathrm{m}$ respectively for the gap set 3.5,3.0, 2.5 and $2.0 \mathrm{~mm}$, respectively. On the other hand, for combination 2, the external magnet was changed to $40 \times 10 \times 10 \mathrm{~mm}$ while the internal magnet was maintained. For the combination, the groove depth increases to 8.95, 6.98, 11.83 and $10.21 \mu \mathrm{m}$ respectively for the same gap setting. The gap and magnet strength combination can be used to adjust grooving depth.

In the next stage, the grooving using the internal and external magnet combination 3 was conducted where magnet size 10x10x40 mm was used for both locations. The groove depth was recorded $73.08 \mu \mathrm{m}$ with the gap between magnet and workpiece of $2.0 \mathrm{~mm}$. The highest groove depth recorded $75.55 \mu \mathrm{m}$ and the gap between magnet and workpiece was $2.5 \mathrm{~mm}$ as shown in Fig 5(d). The gap was then adjusted to 3.0 and $3.5 \mathrm{~mm}$, discover that the depth reduced to 62.15 and $59.39 \mu \mathrm{m}$ respectively as shown in Figure 5(e) and 5(f). It was observed that the groove depth increases dramatically because of higher magnetic field force created in combination tool 3. It is noted that a small difference in gap could impact a big difference in grooving depth. The impact percentage is further amplified in a stringer magnetic field. In this experiment, a fine gap adjustment has reach mechanical limitation in term of gap positioning. Therefore, there is a possibility of error in the setting of gap 2.0 and $2.5 \mathrm{~mm}$ that lead to a deeper groove for the latter.

The magnet combination 1, combination 2, and combination 3 generated average maximum grooves of $3.02,11.83$ and $75.55 \mu \mathrm{m}$ each. It was observed that the grooves were formed with 
depth proportional to the magnetic strength generated from the three magnet combinations. Magnetic field simulation for 10x10x10 mm magnet combination demonstrated a lower magnetic field energy compared to the combination for a larger magnet and a comparison between a closed and opened magnetic circuit has demonstrated a great strength difference.

\section{Conclusions}

Conclusions are summarized as below.

1. A machine with grooving tool constructed with a closed-magnetic tool was controlled in a combined linear and rotational movement was successfully used to create an internal groove, have been designed and fabricated successfully.

2. The magnetic grooving tool can produce a spiral V-shape groove conform with its tool tip shape continuously on a copper pipe internal surface. The depth of the groove could be controlled by adjusting the magnetic field strengths by means of changing the gap between the magnets, selection of type and size of the magnets that are used.

3. Using the magnetic tool with a linear speed $0.3 \mathrm{~mm} / \mathrm{s}$ and gap between magnet and workpiece $2.5 \mathrm{~mm}$ can produce the maximum depth of groove $75.55 \mu \mathrm{m}$ on the as-is surface of the copper pipe by the combination of external and internal neodymium rare earth magnet of 10x10x40 mm size grade N52.

Acknowledgement: The Authors would like to acknowledge the University of Malaya, Malaysia for providing the necessary facilities and resources for this research. This research is partially supported by University of Malaya's Grant (GPF062B-2020).

\section{Declarations}

Funding: University of Malaya's Research Grant No. GPF062B-2020

Conflict of interest: The author declares no conflict of interest.

Availability of data and materials: Yes

Code availability: Not applicable

Author's contributions: Ridha worked on supervision and manuscript improvement, Rony worked on the experiment, manuscript preparation and simulation, Nashrul worked on analysis, Farah worked on manuscript improvement and Moustafa worked on assisting the experiment.

Ethics approval: Not applicable

Content to participate: Not applicable

Consent for publication: The authors declare consent for publication. 


\section{References}

1. Bergles AE (1999) Enhanced heat transfer: Endless frontier, or mature and routine? Applied Optical Measurements, (Springer), pp 3-17.

2. Webb R (1994) Principles of Enhanced Heat TransferWiley-Interscience. New York.

3. Gondrexon N, et al. (2015) Intensification of heat and mass transfer by ultrasound: Application to heat exchangers and membrane separation processes. Ultrasonics sonochemistry 25:40-50.

4. Celik N (2020) Effects of dimples' arrangement style of rough surface and jet geometry on impinging jet heat transfer. Heat Mass Transfer 56(1):339-354.

5. Alsarraf J, et al. (2019) Effect of magnetic field on laminar forced convective heat transfer of MWCNT-Fe $3 \mathrm{O}$ 4/water hybrid nanofluid in a heated tube. Journal of Thermal Analysis Calorimetry 137(5):1809-1825.

6. Léal L, et al. (2013) An overview of heat transfer enhancement methods and new perspectives: Focus on active methods using electroactive materials. International Journal of Heat Mass Transfer 61:505-524.

7. Jadhav M, Awari R, Bibe D, Bramhane A, \& Mokashi M (2016) Review on enhancement of heat transfer by active method. International Journal of Current Engineering Technology 6:221-225.

8. Alam T \& Kim M-H (2018) A comprehensive review on single phase heat transfer enhancement techniques in heat exchanger applications. Renewable Sustainable Energy Reviews 81:813-839.

9. Lambrechts A, Liebenberg L, Bergles AE, \& Meyer JP (2006) Heat transfer performance during condensation inside horizontal smooth, micro-fin and herringbone tubes. Journal of Heat Transfer 128(7):691-700.

10. El-Genk MS \& Ali AFJIJoMF (2010) Enhanced nucleate boiling on copper microporous surfaces. International Journal of Multiphase Flow 36(10):780-792.

11. Liu Z-H, Li Y-Y, \& Bao RJ (2011) Compositive effect of nanoparticle parameter on thermal performance of cylindrical micro-grooved heat pipe using nanofluids. International journal of thermal sciences 50(4):558-568.

12. Ebisu T, Fujino H, \& Torikoshi K (1998) Heat transfer characteristics and heat exchanger performances for R407C using herringbone heat transfer tube. International Refrigeration and Air Conditioning Conference:Paper 434.

13. Miyara A, Otsubo Y, Ohtsuka S, \& Mizuta YJIjor (2003) Effects of fin shape on condensation in herringbone microfin tubes. International Journal of Refrigeration 26(4):417-424.

14. Aroonrat K, et al. (2013) Heat transfer and single-phase flow in internally grooved tubes. International Communications in Heat Mass Transfer 42:62-68.

15. Li W, Chen X, Chen J-X, Sun Z-C, \& Simon TWJJoHT (2017) Shell-side flow condensation of R410A on horizontal tubes at low-mass fluxes. Journal of Heat Transfer 139(1).

16. Zhang G-L, Zhang S-H, Li B, \& Zhang H-Q (2007) Analysis on folding defects of inner grooved copper tubes during ball spin forming. Journal of materials processing technology 184(1-3):393-400.

17. Rotarescu M (1995) A theoretical analysis of tube spinning using balls. Journal of materials processing technology 54(1-4):224-229.

18. Yong L, Hui X, Bin L, Yong T, \& Zeng Z-X (2008) Forming method of axial micro grooves inside copper heat pipe. Transactions of Nonferrous Metals Society of China 18(5):1229-1233. 
19. H T Lim SHK, H D Im, K H Oh and S H Jeong (2008) Fabrication and evaluation of a copper flat micro heat pipe working under adverse-gravity orientation. JOURNAL OF MICROMECHANICS AND MICROENGINEERING.

20. Nikolai Z \& Alexander O (Jul 7 1998) Method and apparatus of producing a surface with alternating ridges and depressions. (U.S. Patents 5775 187).

21. Zubkov N \& Yakomaskin A (2014) Microgrooved Wicks for Heat Pipes Made by Edge Cutting Machining. Second International Conference "Heat Pipes for Space Application"'[Электронный ресурс]: материаль конф.-Электрон. дан.

22. M'hamed B, et al. (2016) A review on why researchers apply external magnetic field on nanofluids. International Communications in Heat Mass Transfer 78:60-67.

23. Liu W, et al. (2019) Impact of oscillating magnetic field on the thermal-conductivity of water-Fe3O4 and water-Fe3O4/CNT ferro-fluids: Experimental study. Journal of Magnetism Magnetic Materials 484:258-265.

24. Wang J, Li G, Zhu H, Luo J, \& Sundén B (2019) Experimental investigation on convective heat transfer of ferrofluids inside a pipe under various magnet orientations. International Journal of Heat Mass Transfer 132:407-419.

25. Asfer M, Mehta B, Kumar A, Khandekar S, \& Panigrahi PK (2016) Effect of magnetic field on laminar convective heat transfer characteristics of ferrofluid flowing through a circular stainless steel tube. International Journal of Heat Fluid Flow 59:74-86.

26. Bergles AE (1999) "Enhanced heat transfer: Endless frontier, or mature and routine?," in Applied Optical Measurements, . J Journal of Enhanced Heat Transfer 6(2-4):3-17.

27. Ramadhan AA, Al Anii YT, \& Shareef AJJ (2013) Groove geometry effects on turbulent heat transfer and fluid flow. Heat and Mass Transfer, 49(2):185-195.

28. Ponnappan RJ (2002) Novel groove-shaped screen-wick miniature heat pipe. Journal of thermophysics heat transfer, 16(1):17-21.

29. Deshpande PA, Inamdar, A. R., \& Gadekar, S. R (2016) Review on Advanced Finishing Processes. International Journal of Advanced Technology in Engineering and Science, 4(3).

30. Kumar H, Singh S, Nanak G, \& Kumar P (2013) Magnetic abrasive finishing-a review. International Journal of Engineering Research \& Technology 2(3).

31. Shinmura T TK, Hatano E (1986) Study on magnetic abrasive finishing (1 Report) - On process principle and a few finishing characteristics. . J JSPE 52:851-857.

32. Ridha MM, Zou Y, \& Sugiyama HJ (2015) Development of a new internal finishing of tube by magnetic abrasive finishing process combined with electrochemical machining. International Journal of Mechanical Engineering and Applications 3(2):22-29.

33. Shewane PG, Gite M, Singh A, \& Narkhede AJIJ (2014) An overview of neodymium magnets over normal magnets for the generation of energy. International Journal on Recent and Innovation Trends in Computing and Communication 2(12):4056-4059.

34. Fraden J (2010) Handbook of modern sensors: physics, designs, and applications (Springer Science \& Business Media, USA). 